JINGJING LIANG, Ph.D. ${ }^{1,2}$

E-mail: 1610013@tongji.edu.cn

XIAONING ZHANG, Ph.D. ${ }^{1}$

(Corresponding Author)

E-mail: cexzhang@tongji.edu.cn

HUANG YAN, Ph.D. candidate ${ }^{1}$

E-mail: tjyh@tongji.edu.cn

${ }^{1}$ School of Economics and Management,

Tongji University, Shanghai 200092, China

${ }^{2}$ Department of Civil and Environmental Engineering,

University of California, Davis, Davis, CA 95616, USA
Intelligent Transport Systems (ITS) Original Scientific Paper Submitted: 11 Jan. 2019 Accepted: 21 Nov. 2019

\title{
EVALUATING THE IMPACTS OF PARKING APP SERVICES ON TRAVELLERS' CHOICE BEHAVIOUR AND TRAFFIC DYNAMICS
}

\begin{abstract}
As the products of intelligent transportation systems, parking apps have become convenient platforms for implementing parking policies, which can be provided as parking app services. This paper proposes a traffic simulation model for evaluating the impacts of parking app services on the travellers' choice behaviour and traffic dynamics. Travellers are assumed to use three types of parking app services: the provision of information on real-time parking lot occupancies, parking reservation, and the display of dynamic parking fees. The behaviour of travellers, such as travellers' mode choices, departure time choices, and learning behaviour, are considered in this model. Numerical experiments show that providing information on real-time parking lot occupancies can be helpful in reducing the use ratio of commercial parking lots, but the effect will ultimately be smoothed during the evolution of traffic dynamics. Moreover, parking reservation is an effective way to reduce travel costs and encourage travellers to choose park-and-ride. Furthermore, dynamic parking fees usually lead to the oscillation of traffic dynamics and travellers' choices, in addition to an increase in travel costs. This model is a useful tool for analysing the impacts of other parking management policies that can be implemented as parking app services and can be a reference for evaluating the impacts of other parking polices.
\end{abstract}

\section{KEY WORDS}

parking app services; parking policies; traffic dynamics; traveller's choice behaviour; learning behaviour theory;

\section{INTRODUCTION}

As products of intelligent transportation systems (ITS), parking apps have been developed to alleviate the growing parking problem. Taking ETCP as an example, with its service, the drivers can easily find locations, parking fees, opening times, and availabilities of nearby parking lots and even use a third-party map app linked to the service when they need route guidance. Moreover, drivers can link their licence plate number and payment account to the ETCP service to enjoy the automatic payment service for parking. This new trend brings many challenges to the adaptability of classic traffic models, which are typically developed based on theoretical derivation and survey data, such as Vickrey's bottleneck model, dynamic traffic assignment techniques and regression approaches [1-4].

Attempts have been made in many related studies to improve the adaptability of these models by introducing these parking services. To name but a few, Caicedo [5] developed a demand assignment model to evaluate the benefits of manipulating real-time parking information and found that improvements of some $10 \%$ in efficiency could be achieved when using a full search procedure. Yang et al. [6] proposed a reservation strategy model of finite parking spaces by modifying the active parking guidance model (APGM). Liang and Zhang [7] proposed a traffic simulation model considering the provision of real-time parking lot information and discussed the impacts of this information on travellers' traffic mode choices. More related studies can be found in the literature [8-10]. However, the existing studies on this subject usually only focus on one type of parking service; these methods still face limitations when the impacts of some advanced parking services must be considered. For instance, if today's parking reservation results can affect the 
travellers' choices tomorrow (both traffic mode and departure time), then travellers who depart during a time interval today may not always choose the same departure time interval tomorrow. In this case, classic models such as the point-queue (P-Q) model, spatial-queue model and cell transmission model, which mainly focus on the quantity of traffic flows, lose their effectiveness in characterizing every traveller's behaviour during day-to-day traffic dynamics $[1,3,4]$. As parking services are becoming increasingly customizable in the era of parking apps, an adaptable traffic model should be introduced to meet this need.

This paper aims to bridge this gap and evaluate the impacts of parking app services on the traffic dynamics and travellers' behaviour. Three types of parking services are investigated in this paper, namely, the provision of information on real-time parking lot occupancies, parking reservation services, and the display of dynamic parking fees for commercial parking lots. In addition, a third-party map service is treated as the basic service in this model. This service is not discussed in details because the effectiveness and popularity of this service have been widely discussed [11-13]. Moreover, learning behaviour theory is adopted to incorporate the impact of historical traffic dynamics during day-to-day evolution instead of directly incorporating information about traffic dynamics. The reason for this approach is because if the information about traffic dynamics such as routing information and the congestion level of each road are considered, the route choice problem has to be jointly considered with the traffic mode choice problem. Since the route choice problem is not the key point of this paper, each traffic mode in each origin-destination (OD) pair is assumed to be an equivalent path, which can be helpful in investigating the impacts of parking app services on traffic dynamics more intuitively.

The main work of this paper can be summarized as follows. First, a simulation framework is designed to describe the travellers' behaviour in the day-today morning commute traffic process, including travellers' traffic mode choices, their departure time choices and the influence of parking app services on the travellers' behaviour. In the proposed framework, the within-day traffic is formulated based on the P-Q model [14], and the day-to-day evolution of traffic dynamics is formulated based on the learning behaviour theory [15]. Second, a traffic simu- lation model is proposed by considering the three parking services. Finally, the rationality of the proposed model is verified by numerical experiments, and the impacts of parking app services on travellers' behaviour and traffic dynamics are discussed via a scenario comparison. The contributions of this paper are as follows: (1) a traffic simulation model for the application of parking apps is proposed; (2) extensive experiments are conducted to demonstrate the rationality of the proposed model in imitating travellers' behaviour and real-world traffic dynamics; and (3) the impacts of parking app services on travellers' behaviour and traffic dynamics are analysed by taking three parking services as examples.

The remainder of this paper is organized as follows. Section 2 describes the general simulation framework and formulates the proposed model. Section 3 presents the experimental results demonstrating the rationality of the proposed model and the impacts of parking apps on traffic dynamics and travellers' behaviour. Section 4 provides the conclusions of this paper and discusses potential applications of the proposed model in further studies.

\section{TRAFFIC SIMULATION MODEL}

Consider a widely discussed many-to-one traffic network with an insufficient supply of parking [1618] that connects several residential areas (RAs) with a central business district (CBD). Assume that a fixed number of travellers depart from the origin of every OD pair to the CBD during morning peak hours every day. Each of these travellers owns a private car so that they can freely choose to take mass rapid transit (MRT), drive a vehicle (DV) or park-and-ride $(\mathrm{P}+\mathrm{R})$. To imitate the insufficient supply of parking, it is supposed that there are only two parking lots located at the CBD, a free parking lot with limited parking spaces and a commercial parking lot with ample parking spaces. However, the parking fee of commercial parking lots is expensive for every traveller. If a traveller arrives at the CBD but fails to obtain a free parking space, the traveller has to park in the commercial parking lot. In addition, suburban areas (SUs) in the $\mathrm{P}+\mathrm{R}$ traffic mode also provide ample free parking spaces to encourage travellers to choose $\mathrm{P}+\mathrm{R}$.

According to the learning behaviour theory $[15,19]$, travellers will adjust their departure times and traffic mode choices based on their predicted travel costs and experienced travel costs; thus, the calculation of travel costs is the key issue in 


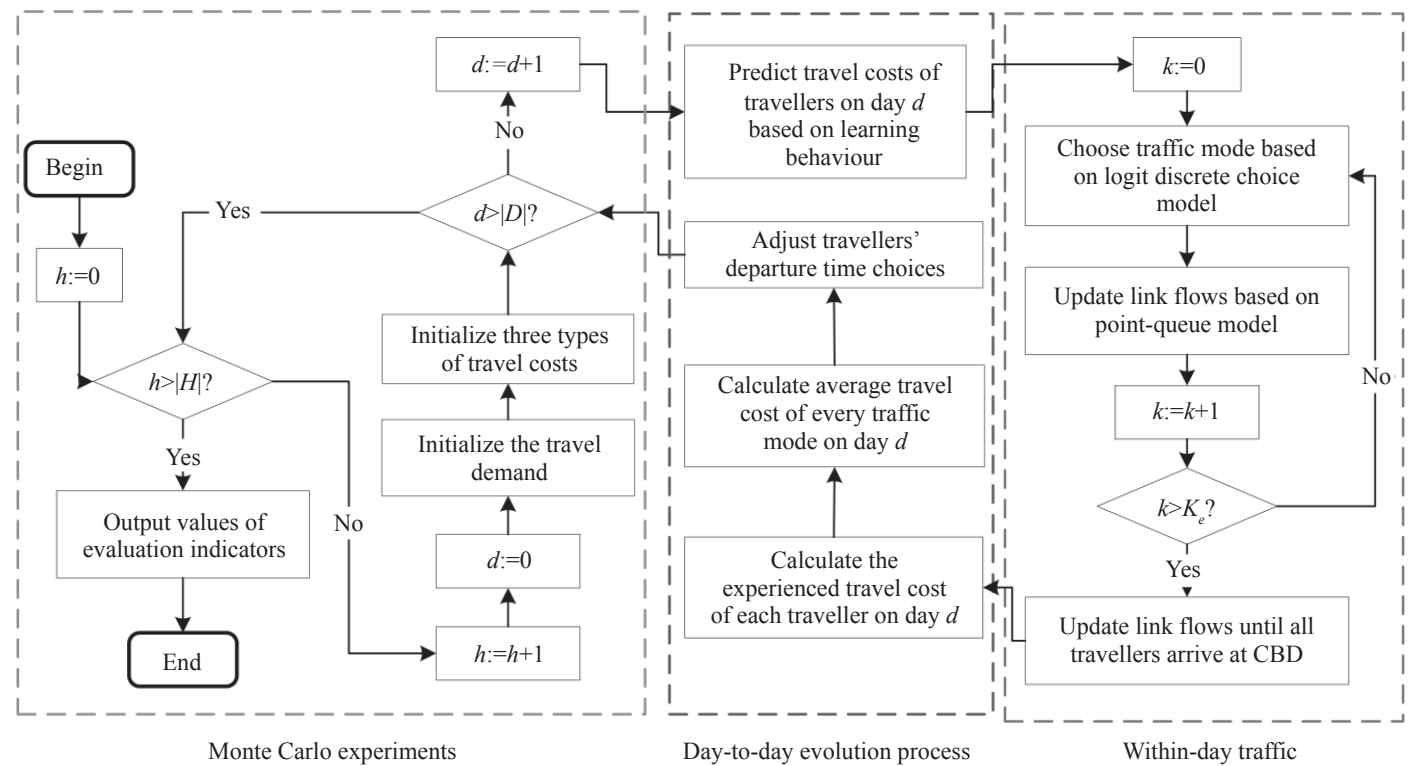

Figure 1-General simulation framework

this model. As shown in Figure 1, the following three types of travel costs are involved in this paper: the traveller's experienced travel cost, the traveller's predicted travel cost, and the daily average travel cost of travellers who depart during the same time interval. In addition, to describe the day-to-day evolution of traffic dynamics, general activities in the daily morning commute process are formulated step by step, including initializing the travel demand and three types of travel costs, predicting travel costs based on the learning behaviour theory, the within-day traffic process, calculating daily average travel costs, and adjusting travellers' departure time choices.

It should be noted that uncertainty is introduced into this model for two reasons. One reason is that the traveller's mode choice behaviour is described by the logit discrete choice model [3] in the formulation of within-day traffic because travellers will choose traffic modes by chance according to their utilities. Another reason is that the process of parking reservation and competition are both uncertain for every traveller, and the daily reservation and competition results must be obtained by randomized experiments. Therefore, Monte Carlo methods should be applied to address this uncertainty [20].

Figure 1 presents the general simulation framework of the proposed model, which has three hierarchies of loops from left to right. The first loop is the Monte Carlo simulation process, the second loop contains major activities of travellers and the calculation methods of travel costs during the day-to-day evolution process, and the last loop describes the within-day traffic dynamics. In the following subsections, the formulations and explanations of the simulation steps are elaborated, and the methods for introducing three types of parking services are also presented.

\subsection{Initialization of travel demand}

Denote by $i \in Q^{w}:=\left\{0,1,2 \ldots,\left|Q^{w}\right|-1\right\}$ the index of travellers, where $Q^{w}$ is the set of travellers in OD pair $w \in W$ and $\left|Q^{w}\right|$ is the total number of travellers in OD pair $w$. Let $F^{w}(d, k)$ be the cumulative function of travel demand on day $d$ up to time interval $k$; it can be defined as

$F^{w}(d, k)=\left\{\begin{array}{ll}\sum_{u=0}^{k} f^{w}(d, u) & \forall k \in K_{1} \\ \left|Q^{w}\right| & \forall k \in K_{2}\end{array} \quad \forall d \in D, w \in W\right.$

In Equation 1, $d \in D:=\{0,1,2, \ldots,|D|-1\}$ is the index of the day, where $D$ is the set of $d$ and $|D|$ is the total number of simulation days. The departure time period of the travellers in the RA is denoted by $\left[T_{0}, T_{e}\right]$ and divided into equal-length time intervals $K_{1}:=\left\{0,1,2, \ldots, K_{e}\right\}$, and the length of a unit time interval is $\Delta t=\frac{T_{e}-T_{0}}{\left|K_{1}\right|}$. Denote by $T_{K}$ the time that the last traveller arrives at the $\mathrm{CBD}$, and discretize the time interval $\left(T_{e}, T_{K}\right]$ as $K_{2}:=\left\{K_{e}+1, \ldots,|K|-1\right\}$; then, the whole time period is $K=K_{1} \cup K_{2}$.

\subsection{Three types of travel costs}

For a clearer formulation, some indices in this model are defined as follows: the traffic mode type is indexed by $m \in M:=\{1,2,3\}$, where $m=1$ stands 
for MRT, $m=2$ stands for DV, and $m=3$ stands for $\mathrm{P}+\mathrm{R}$; the pair of day and time interval is indexed by $(d, k) \in D K:=\{d \in D, k \in K\}$; the link in the network is indexed by $a \in A$. Therefore, if traveller $i$ in OD pair $w$ departs during time interval $k$ and chooses traffic mode $m$ on day $d$, traveller's experienced travel cost $c_{m}^{w, e}(i, d, k)$ can be defined as

$$
\begin{aligned}
& c_{m}^{w, e}(i, d, k)=\sum_{a \in A}\left\{\left[\tau_{a}+\alpha T_{a}^{e}(d, k)\right] \varepsilon_{a m}^{w}+\right. \\
& +\beta \max \left\{0, t^{*}-k-T_{a}^{e}(d, k) \mathcal{E}_{a m}^{w}\right\}+ \\
& \left.+\gamma \max \left\{0, k+T_{a}^{e}(d, k) \mathcal{E}_{a m}^{w}-t^{*}\right\}\right\}+\phi(d) Z^{w}(i, d, k) \\
& \forall i \in Q^{w},(d, k) \in D K, m \in M, w \in W
\end{aligned}
$$

In Equation 2, $t^{*}$ is the desired arrival time interval at work for all travellers; $\alpha$ is the value of time (VOT); $\beta$ and $\gamma$ are the early and late arrival penalties (for a unit of time), respectively; and $\beta<\alpha<\gamma$, which is consistent with empirical evidence. Other notations are defined as follows: $\varepsilon_{a m}^{w} \in\{0,1\}$ is the indicator for identifying whether link $a$ is used in traffic mode $m$ in OD pair $w ; \tau_{a}$ is the fixed travel cost (e.g., gas cost of driving or transit fee) of link $a ; T_{a}^{e}(d, k)$ is the actual travel time on link $a$ experienced by a traveller who departs during time interval $k ; \phi(d)$ is the parking fee of the commercial parking lot during the morning rush hour on day $d$; $Z^{w}(i, d, k) \in\{0,1\}$ is the binary variable for indicating whether traveller $i$ has obtained a free parking space after arrival when departing during time interval $k$ on day $d$ in OD pair $w$. Therefore, the first term in Equation 2 is the actual travel cost related to the traffic network, the second and third terms are early and late penalties, respectively, and the last term is the parking fee that the traveller must pay if the traveller fails to obtain a free parking space after having driven to the CBD.

\subsection{Initialization of travel costs}

Experienced travel cost. For time interval $k$ on day 0 , the actual travel time $T_{a}^{e}(0, k)$ of link $a$ is initialized by its free-flow travel time, which means

$$
T_{a}^{e}(0, k)=t_{a}^{0} \quad \forall k \in K, a \in A
$$

where $t_{a}^{0}$ is the free-flow travel time of link $a$. Thus, the initial experienced travel $\operatorname{cost} c_{m}^{w, e}(i, 0, k)$ of traveller $i$ can be written as

$$
\begin{aligned}
& c_{m}^{w, e}(i, 0, k)=\sum_{a \in A}\left\{\left[\tau_{a}+\alpha T_{a}^{e}(0, k)\right] \varepsilon_{a m}^{w}+\right. \\
& +\beta \max \left\{0, t^{*}-k-T_{a}^{e}(0, k) \mathcal{E}_{a m}^{w}\right\}+ \\
& \left.+\gamma \max \left\{0, k+T_{a}^{e}(0, k) \mathcal{E}_{a m}^{w}-t^{*}\right\}\right\}+\phi(0) Z^{w}(i, 0, k) \\
& \forall i \in Q^{w}, k \in K, m \in M, w \in W
\end{aligned}
$$

Predicted travel cost. In the parking app, the predicted travel $\operatorname{cost} c_{m}^{w, p}(i, 0, k)$ is initialized by the traveller's initial experienced travel cost, which means

$c_{m}^{w, p}(i, 0, k)=c_{m}^{w, e}(i, 0, k) \quad \forall i \in Q^{w}, k \in K, m \in M, w \in W$

Average travel cost. In OD pair $w$, the initial average travel cost $\bar{c}_{m}^{w, e}(0, k)$ is equivalent to the initial experienced travel cost of travellers who depart during the same time interval $k$ on day 0 , which means

$\bar{c}_{m}^{w, e}(0, k)=c_{m}^{w, e}(i, 0, k) \quad \forall i \in Q^{w}, k \in K, m \in M, w \in W$

\subsection{Predicted travel cost based on learning behaviour theory}

The prediction method of travel costs in the parking app is formulated based on the learning behaviour, which can be presented as follows:

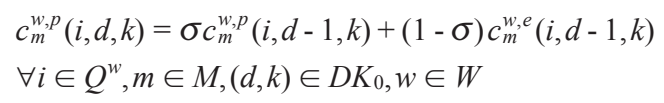

Equation 7 introduces a new set $D K_{0}:=\{d \in D \backslash\{0\}$, $k \in K\}$ to ensure that $d-1 \geq 0 ; \sigma \in(0,1)$ is the learning factor in the learning behaviour theory $[15,19]$; $c_{m}^{w, p}(i, d-1, k)$ is the predicted travel cost of the previous day; and $c_{m}^{w, e}(i, d-1, k)$ is the experienced travel cost of the previous day.

\subsection{Within-day traffic process}

\section{$P-Q$ model}

The general traffic process of the morning commute can be described by four variables in the P-Q model; namely, the in-flow rate $p_{a}(d, k)$, the out-flow rate $v_{a}(d, k)$, the queue length $q_{a}(d, k)$, and the actual travel time $T_{a}(d, k)$ [14]. To simplify the expressions, $\delta_{a m}^{w} \in\{0,1\}$ is defined as the indicator for identifying whether link $a$ is the starting link of traffic mode $m$ in OD pair $w$. Then, the link set of the traffic network can be divided into two separate sets: $A_{1}:=\left\{a \mid \sum_{m \in M} \delta_{a m}^{w}=1, a \in A, w \in W\right\}$ and $\mathrm{A}_{2}:={\mathrm{A} \backslash \mathrm{A}_{1}}_{1}$.

In-flow rate. Denote $X_{m}^{w}(i, d, k) \in\{0,1\}$ as the indicator of whether traveller $i$ in OD pair $w$ has chosen traffic mode $m$ on day $d$, the in-flow rate of link $a \in A_{1}$ can be defined as

$$
\begin{aligned}
& p_{a}(d, k)=\sum_{w \in W} \sum_{m \in M} \sum_{i \in Q^{w}} f^{w}(d, k) X_{m}^{w}(i, d, k) \delta_{a m}^{w} \\
& \forall(d, k) \in D K, a \in A_{1}
\end{aligned}
$$


Denote $\pi_{a b}^{w}\{0,1\}$ as the indicator for identifying whether link $b$ is upstream of link $a$, and the in-flow rate of link $a$ in $A_{2}$ can be obtained by

$p_{a}(d, k)=\sum_{b \in A} \pi_{a b}^{w} v_{b}(d, k) \quad \forall(d, k) \in D K, a \in A_{2}$

where $v_{b}(d, k)$ is the out-flow rate of link $b$.

Out-flow rate. If $0 \leq k \leq\left\lceil t_{a}^{0}\right\rceil$, the out-flow rate of link $a$ is

$v_{a}(d, k)=0 \quad \forall(d, k) \in D K, a \in A$

If $\left\lceil t_{a}^{0}\right\rceil<k$, the out-flow rate of link $a$ should be

$$
\begin{aligned}
v_{a}(d, k)= & \begin{cases}\min \left(C_{a}, p_{a}\left(d, k-\left\lceil t_{a}^{0}\right]\right)\right) & \text { if } q_{a}(d, k)=0 \\
C_{a} & \text { if } q_{a}(d, k) \neq 0\end{cases} \\
& \forall(d, k) \in D K, a \in A
\end{aligned}
$$

In Equation 11, $C_{a}$ is the bottleneck capacity of link $a$, and $q_{a}(d, k)$ is the queue length on link $a$ during time interval $k$ on day $d$.

Queue length. The queue length on link $a$ during time interval 0 is

$q_{a}(d, 0)=0 \quad \forall d \in D, a \in A$

For other time intervals, the queue length can be obtained using the following recurrence formula:

$q_{a}(d, k+1)-q_{a}(d, k)=$
$= \begin{cases}0 & \forall 0 \leq k \leq\left\lceil t_{a}^{0}\right\rceil, \\ p_{a}\left(d, k-\left\lceil t_{a}^{0}\right]\right)-v_{a}(d, k) & \forall\left\lceil t_{a}^{0}\right]<k \leq|K|-1, \\ \forall d \in D, a \in A\end{cases}$

Actual travel time. The actual travel time on link $a$ for time interval $k$ on day $d$ is calculated by

$T_{a}^{e}(d, k)=\left\lceil t_{a}^{0}\right\rceil+\frac{q_{a}\left(d, k+\left\lceil t_{a}^{0}\right\rceil\right)}{C_{a}} \quad \forall(d, k) \in D K, a \in A$

\section{Traveller's mode choice behaviour based on the logit model}

Denote by $n_{\text {park }}(d, k)$ the real-time parking lot occupancy. The dynamic parking fee of the commercial parking lot on day $d$ is denoted by $\phi(d)$, and its influence on travellers' behaviour is characterized by a risk value of the remaining parking spaces $G(\phi(d))$. Assume that $G(\phi(d))$ is a monotonically increasing function of $\phi(d)$ because travellers usually tend to take higher risks when $\phi(d)$ decreases.

Without the parking reservation service. Let $N$ denote the total number of free parking spaces in the CBD, and let $\chi_{a m}^{w}\{0,1\}$ denote the indicator of whether the CBD is the end of link $a$ for traffic mode $m$ in OD pair $w$; then, the real-time remaining number of parking spaces $n_{\text {park }}(d, k)$ can be calculated by

$$
\begin{aligned}
& n_{\text {park }}(d, k)=\max \left\{0, N-\sum_{w \in W} \sum_{k \in K} \sum_{m=2} v_{a}(d, k) \chi_{a m}^{w}\right\} \\
& \forall(d, k) \in D K
\end{aligned}
$$

For traveller $i$, if the remaining number of free parking spaces $n_{\text {park }}(d, k)$ is greater than the traveller's risk value such that

$n_{\text {park }}(d, k)>G(\phi(d)) \quad \forall d \in D, k \in K$

The traveller will choose a traffic mode among MRT, DV and P+R. In this case, the traveller's mode choice behaviour is formulated by

$$
\begin{aligned}
& P_{m}^{w}(i, d, k)=\frac{\exp \left(-\theta c_{m}^{w, p}(i, d, k)\right)}{\sum_{j \in M} \exp \left(-\theta c_{j}^{w, p}(i, d, k)\right)} \\
& \forall i \in Q^{w},(d, k) \in D K, m \in M, w \in W
\end{aligned}
$$

where $P_{m}^{w}(i, d, k)$ is the probability of choosing traffic mode $\mathrm{m}$ for traveller $i$ who departs during time interval $k$ on day $d$, which is related to the uncertainty of the traveller's traffic mode choice based on the logit discrete model [3]; $\theta$ is the given parameter in this model. Therefore, the traffic mode choice result $X_{m}^{w}(i, d, k) \in\{0,1\}$ can be obtained during simulation experiments according to the following Equation 18:

$$
\begin{aligned}
& \operatorname{Pr}\left\{X_{m}^{w}(i, d, k)=1\right\}=P_{m}^{w}(i, d, k) \\
& \forall i \in Q^{w},(d, k) \in D K, m \in M, w \in W
\end{aligned}
$$

If the remaining number of free parking spaces is lower than the risk value of travellers, which means

$n_{\text {park }}(d, k) \leq G(\varphi(d)) \quad \forall d \in D, k \in K$

then the traveller will have no opportunity to choose $\mathrm{DV}$ and can merely choose MRT or $\mathrm{P}+\mathrm{R}$. Then, $X_{m}^{w}(i, d, k) \in\{0,1\}$ is obtained by

$$
\begin{aligned}
& \operatorname{Pr}\left\{X_{m}^{w}(i, d, k)=1\right\}=P_{m}^{w}(i, d, k) \\
& \forall i \in Q^{w},(d, k) \in D K, m \in M\{\{2\}, w \in W
\end{aligned}
$$

With the parking reservation service. Consider the case in which the parking reservation service is provided in the parking app, whereby travellers can reserve a parking space in the free parking lot for the next day. If traveller $i$ has successfully reserved a free parking space for day $d$, then the traveller will choose DV on day $d$, so $X_{2}^{w}(i, d, k)$ is equal to 1 . Otherwise, the traveller has to choose MRT or $\mathrm{P}+\mathrm{R}$; thus, $X_{m}^{w}(i, d, k) \in\{0,1\}$ should be calculated using Equation 20.

\subsection{Calculate daily average travel costs}

For the selected traffic mode $m^{*} \in M$, the experienced travel cost $c_{m^{*}}^{w, e}(i, d, k)$ of traveller $i$ can be obtained using Equation 2. For the unselected 
traffic mode $m \in M \backslash\left\{m^{*}\right\}$ of traveller $i$, the experienced travel cost $c_{m}^{w, e}(i, d, k)$ should be set as the average travel cost in each OD pair, which means

$$
\begin{aligned}
& c_{m}^{w, e}(i, d, k)=\bar{c}_{m}^{w, e}(d, k) \\
& \forall m \in M\left\{m^{*}\right\}, i \in Q^{w},(d, k) \in D K, w \in W
\end{aligned}
$$

In Equation $21, \bar{c}_{m}^{w, e}(d, k)$ is obtained by the following logic: let $x_{m}^{w}(d, k)$ be the number of travellers who choose traffic mode $m$ within time interval $k$ on day $d$ such that

$$
\begin{aligned}
& x_{m}^{w}(d, k)=\sum_{i \in Q^{w}} X_{m}^{w}(i, d, k) \quad \forall m \in M,(d, k) \in D K, w \in W \\
& \quad \text { If } x_{m}^{w}(d, k)=0 \text {, the average travel cost } \bar{c}_{m}^{w, e}(d, k) \text { is } \\
& \bar{c}_{m}^{w, e}(d, k)=c_{m}^{w, e}(i, 0, k) \\
& \forall m \in M, i \in Q^{w},(d, k) \in D K, w \in W
\end{aligned}
$$

otherwise,

$$
\begin{aligned}
& \bar{c}_{m}^{w, e}(d, k)=\frac{1}{x_{m}^{w}(d, k)} \sum_{i \in Q^{w}} c_{m}^{w, e}(i, d, k) X_{m}^{w}(i, d, k) \\
& \forall m \in M,(d, k) \in D K, w \in W
\end{aligned}
$$

\subsection{Adjustment of travellers' departure time choices}

As known, the travellers have tolerance values for adjusting their status. For instance, a traveller may only accept departing at most 30 minutes earlier or later than their current departure time. This phenomenon is caused by 'user inertia', as summarized by Liu et al. [21]. In this paper, the user inertia is also considered. All travellers are assumed to have the same tolerance value of $\Delta k$ time intervals; then, the adjustment of travellers' departure time choice can be stated as follows.

\section{Without parking reservation service}

Let $k^{*} \in K$ denote the current departure time interval, $K_{l b}:=\max \left\{0, k^{*}-\Delta k\right\}$ denotes the lower bound of the departure time interval, and $K_{u b}$ := $\min \left\{k^{*}+\Delta k, K_{e}\right\}$ denotes the upper bound of the departure time interval. If a traveller's actual travel cost meets

$$
\begin{aligned}
& c_{m}^{w, e}\left(i, d, k^{*}\right)-\min _{K_{l b} \leq k \leq K_{u b}} \bar{c}^{w, e}(d, k)>\Delta \varepsilon, \\
& \forall i \in Q^{w}, d \in D, w \in W
\end{aligned}
$$

where $\Delta \varepsilon$ is the bias of travel costs that the traveller can endure and $\Delta \varepsilon>0$, then the traveller will depart during time interval

$$
k^{\prime}=\arg _{K_{l b} \leq k \leq K_{u b}} \bar{c}^{w, e}(d, k) \quad \forall d \in D, w \in W
$$

on day $d+1$; otherwise, the traveller's departure time choice will not change. In Equations 25 and 26, the average travel cost $\bar{c}^{w, e}(d, k)$ of all traffic modes is obtained by

$$
\bar{c}^{w, e}(d, k)=\frac{1}{|M|} \sum_{m \in M} \bar{c}_{m}^{w, e}(d, k)
$$$$
\forall m \in M,(d, k) \in D K, w \in W
$$

\section{With parking reservation service}

Consider the case in which the free parking lot provides parking reservation service, while the commercial parking lot does not. If a traveller fails to reserve a free parking space for day $d$, but succeeds in doing so for day $d+1$, the traveller will choose their best departure time interval $k^{\prime}$ for day $d+1$ within the range of $\Delta T:=\left[k^{*}, \frac{t^{*}-\sum_{a \in A} t_{a}^{0} \mathcal{E}_{a 2}^{w}}{\Delta t}\right]$ for all OD pairs $w \in W$. In this case, traveller $i$ will consider only the average traffic cost of DV. Therefore, if

$c_{m^{*}}^{w, e}\left(i, d, k^{*}\right)-\min _{k \in \Delta T} \bar{c}_{2}^{w, e}(d, k)>\Delta \varepsilon$

$\forall i \in Q^{w}, d \in D, w \in W$

the traveller will depart during time interval $k^{\prime}$, which has the minimum average cost $\bar{c}^{w, e}(d, k)$ on the next day; otherwise, the traveller's departure time choice will not change. If a traveller fails to reserve a space for day $d+1$, regardless of whether the traveller had reserved a space for day $d$, the traveller will choose the departure time interval $k^{\prime}$ on day $d$ following the rule in Equations 25-27.

\subsection{Evaluation criterion}

Denote $h \in H:=\{1,2, \ldots,|H|\}$, where $H$ is the set and $|H|$ is the total number of simulation experiments, as the index of the Monte Carlo simulation experiments. The average total travel cost $\overline{T C}^{w}(d)$ in OD pair $w$ on day $d$ can be calculated using

$$
\begin{aligned}
& \overline{T C}^{w}(d)=\frac{1}{|H|} \sum_{h \in H} \sum_{m \in M} \sum_{k \in K} \sum_{i \in Q^{w}} c_{m}^{w, e}(i, d, k) X_{m}^{w}(i, d, k) \\
& \forall d \in D, w \in W
\end{aligned}
$$

The total travel cost of an evolving dynamic traffic system usually tends to converge to a stable value or has significant regularity. As long as $|D|$ is large enough, $\overline{T C}(d)$ will converge to a fixed value (or obtain a significant regular value range). At this point, the stable total travel cost $\overline{T C}^{w}$ can be obtained using

$$
\overline{T C}^{w}=\lim _{d \rightarrow \infty} \overline{T C}^{w}(d) \quad \forall d \in D, w \in W
$$

\section{NUMERICAL EXPERIMENTS AND ANALYSES}

Five scenarios are designed to investigate the impacts of the three types of parking app services (see Table 1). In this table, ' $x$ ' means that the parking service is not provided in the corresponding scenario, while ' $V$ ' has the opposite meaning. 
Liang J, Zhang X, Yan H. Evaluating the Impacts of Parking App Services on Travellers' Choice Behaviour and Traffic Dynamics

Table 1 - Parking services provided in five scenarios

\begin{tabular}{||c|c|c|c||}
\hline Scenario & Real-time parking lot occupancies & Parking reservation & Parking fee (yuan) \\
\hline \hline A & $\times$ & $\times$ & $\phi_{1}(d)=80$ \\
\hline B & $\sqrt{ }$ & $\times$ & $\phi_{1}(d)=80$ \\
\hline C & $\times$ & $\sqrt{ }$ & $\phi_{1}(d)=80$ \\
\hline D & $\sqrt{ }$ & $\times$ & $\phi_{2}(d)=70 \cdot \sin (d \cdot \pi / 15)+80$ \\
\hline E & $\sqrt{ }$ & $\times$ & $\phi_{3}(d)=70 \cdot \sin (d \cdot \pi / 30)+80$ \\
\hline
\end{tabular}

\subsection{Parameter settings}

The departure time period $\left[T_{0}, T_{\mathrm{e}}\right]$ during the daily morning commute is discretized into $K_{e}$ equallength time intervals. Specifically, suppose $\left[T_{0}, T_{e}\right]$ is [7:00, 9:00], the desired arrival time at work is 9:00, and the length of each time interval is $\Delta t=5$ minutes; then, $K_{e}=24$ and $t^{*}=24$. The end time of the morning commute $T_{K}$ can be determined after finishing each experiment, and the last time interval $|K|$ is always no smaller than both $K_{e}$ and $t^{*}$. According to the current wages in China, assume the VOT $\alpha$ is 12 yuan/ hour, the penalty of early arrival $\beta$ is 4.2 yuan/hour, and the penalty of late arrival $\gamma$ is 21.6 yuan/hour.

Figure 2 presents the numerical network. The initial departure rate of day $0, f^{w}(0, k)$, is generated by

$$
f^{v}(0, k)= \begin{cases}3 \mu C_{D V}^{w} \frac{k}{K_{e}}, & \forall k \in\left[0, \frac{K_{e}}{3}\right], \\ \mu C_{D V}^{w}, & \forall k \in\left(\frac{K_{e}}{3}, \frac{2 K_{e}}{3}\right], w \in W \\ 3 \mu C_{D V}^{w}\left(1-\frac{k}{K_{e}}\right), \forall k \in\left(\frac{2 K_{e}}{3}, K_{e}-1\right],\end{cases}
$$

which was used by Nie and Zhang [14] in their research. In Equation 31, $C_{D V}^{w}$ is the bottleneck capacity of the DV link that directly connects the origin of OD pair $w$ and the CBD, $\mu$ is the excess coefficient factor of traffic flow on the link, and $\mu$ is equivalent to 2.5 . Therefore, the travel demand in the three OD pairs is 2,487 travellers, 3,172 travellers, and 3,652 travellers, respectively; thus, the total travel demand in the whole network is 9,311 travellers. The free parking lot in the CBD has only $N=1,500$ parking spaces, while the commercial parking lot and suburban parking lots can provide ample parking spaces.

Other parameters are set as follows: during the process of departure time adjustment, all travellers have the same tolerance value, $\Delta k=6$ time intervals, and the same travel cost bias $\Delta \varepsilon=0.1$ yuan. The learning factor $\sigma$ is 0.7 , the logit parameter $\theta$ is 0.8 , the total number of simulation days $|D|$ is 180 , and the total simulation time $|H|$ is 10,000 . The risk function is $G(\phi(d))=10 \times \ln (\phi(d)+1)$ for all $\phi(d) \geq 0$. A simulation program was developed and coded in $\mathrm{C}++$ using $\mathrm{Mi}-$ crosoft Visual Studio Community 2017. The numerical experiments were performed on a Windows 10 system with the following properties: Intel ${ }^{\circledR} \mathrm{Xeon}^{\circledR}$ CPU E5-2609v3@1.90 GHz × 2 and 32 GB RAM.

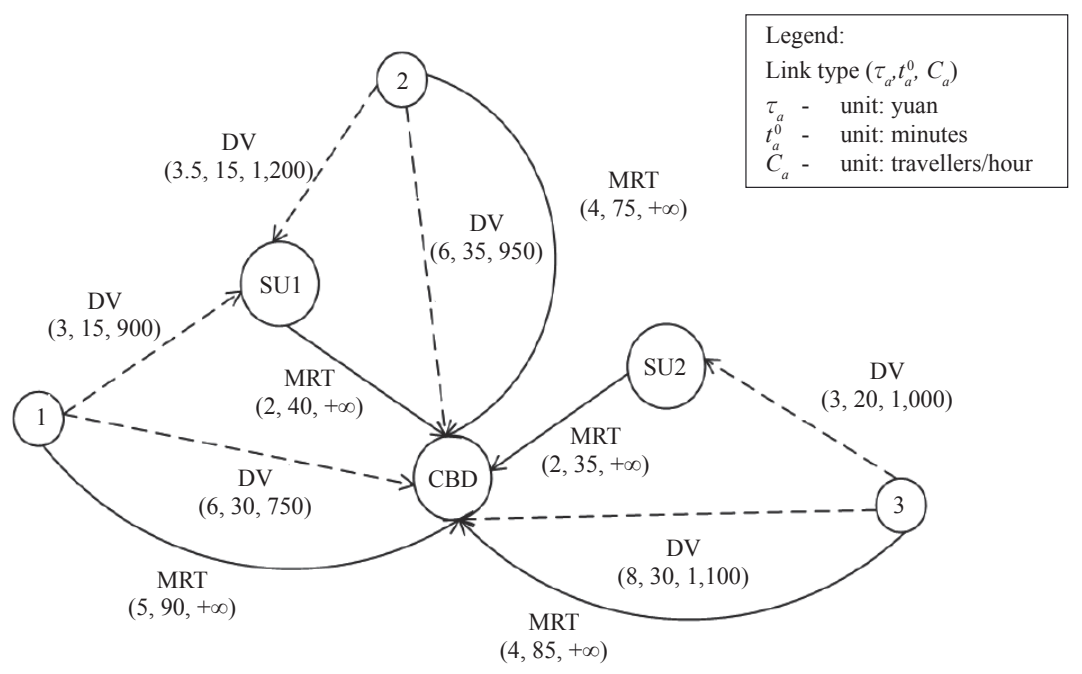

Figure 2-Example traffic network 


\subsection{Rationality test}

In this subsection, scenario A is taken as an example to verify the rationality of the proposed simulation model. Figure $3 a$ shows the evolutionary trajectory of the total travel cost $\overline{T C}{ }^{w}(d)$ of three OD pairs in scenario A. Note that as the simulation day $d$ increases, $\overline{T C}^{w}(d)$ decreases rapidly. When $d$ is greater than 10 days, $\overline{T C}^{w}(d)$ does not decrease further and converges to a relatively stable state. Figure $3 b$ shows the changes in the total departure rates in scenario A. The total number of simulation days $|D|$ has been set to $30,60,90,120,150$ and 180 , and the departure rate curves on the last day in each case are plotted in different colours. Clearly, almost all travellers prefer to depart during [7:20, 8:00] when the desired arrival time is 9:00 regardless of which traffic mode they choose and how large the total simulation days $|D|$ are, and this finding is basically consistent with the real-world situation.

Other detailed results of scenario A can be found in Figure 4 and Table 2. Approximately 235.18 travellers used the commercial parking lot in the CBD on the last day, and the morning commute ended at 9:31 on average. A similar phenomenon is also found in the other four scenarios. Therefore, the proposed model can ensure rational results in simulating the traffic dynamics.

\subsection{Impacts of parking app services on travellers' behaviour}

\subsubsection{Provision of information on real-time parking lot occupancies}

In scenario B, travellers can find the real-time parking lot occupancies in the parking app, the parking reservation service is not provided, and the parking fee is $\phi_{1}(d)=80$ yuan (see Table 1 ). The results of scenarios A and B are summarized in Table 2. The total travel cost of the whole network on the last day in scenario B is $216,461.30$ yuan, which is lower than that in scenario A $(217,240.30$ yuan). Considering the traffic mode choices of travellers, it can be found that fewer travellers chose DV and MRT in scenario B than in scenario A, although only to a

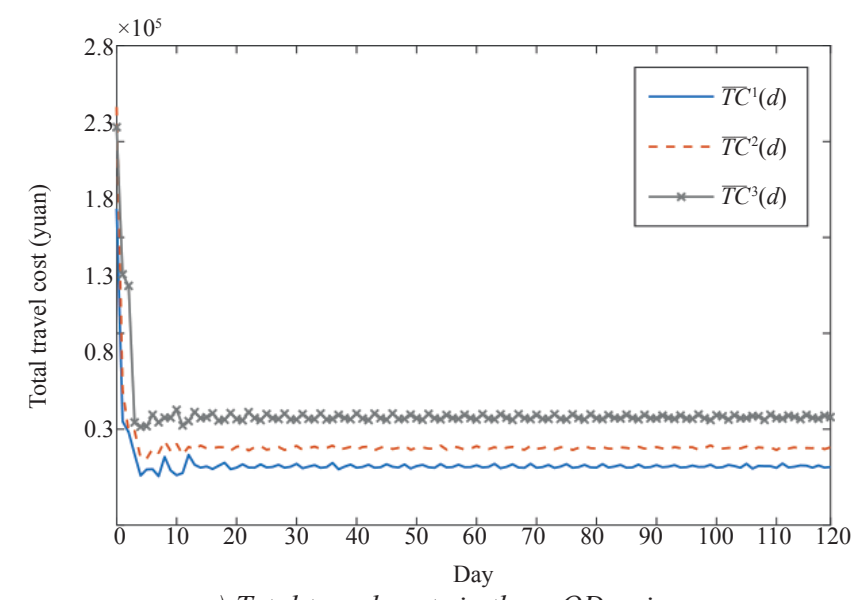

a) Total travel costs in three OD pairs

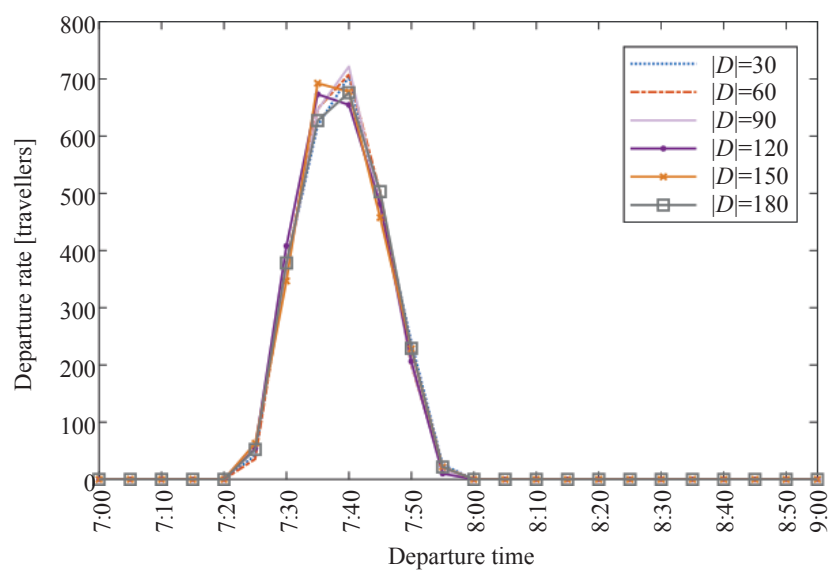

b) Total departure rates of travellers for different $|D|$

Figure 3 -Experiment results of scenario A 


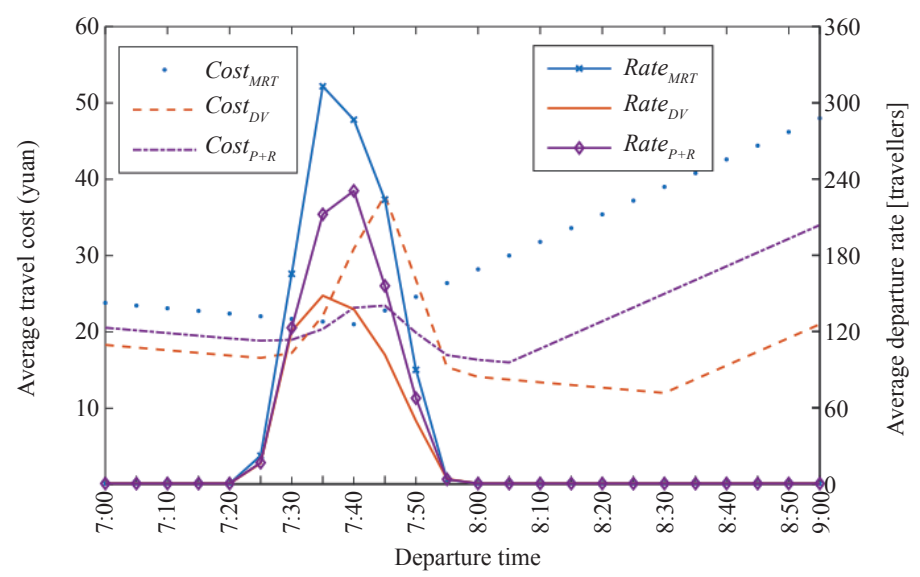

a) $1 \rightarrow C B D$

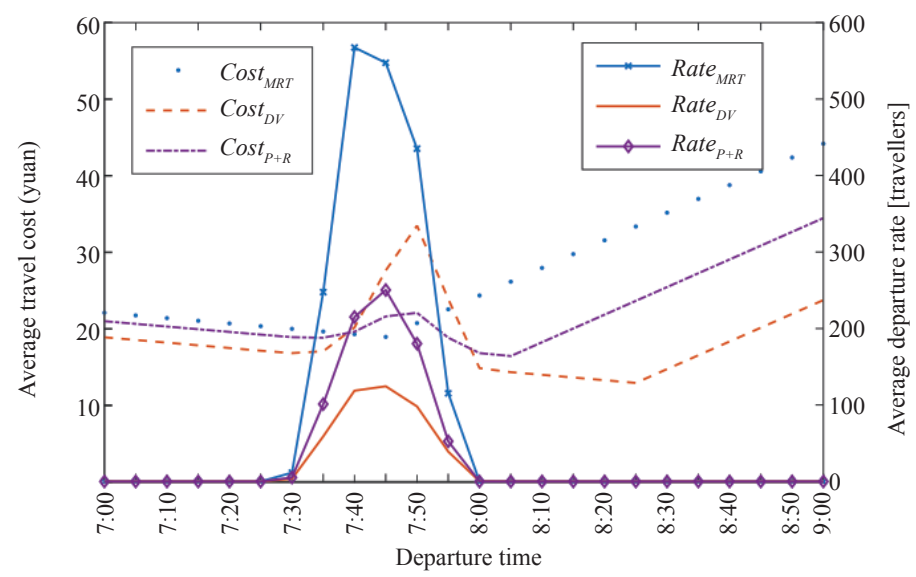

b) $2 \rightarrow C B D$

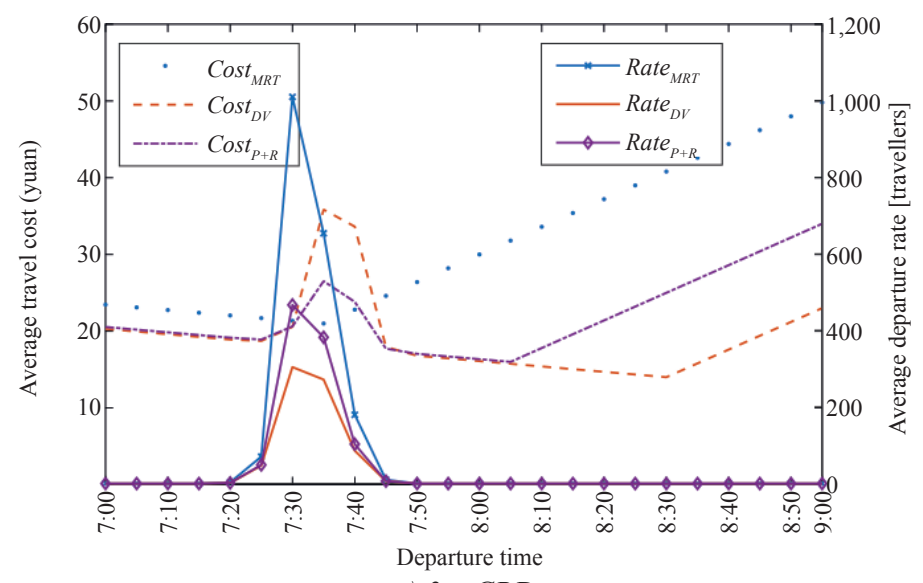

c) $3 \rightarrow C B D$

Figure 4 - Average travel costs and departure rates of travellers in scenario A

slight degree. Moreover, as shown in Figures $4 a$ and $5 a$, the distributions of departure rates and average travel costs in the two scenarios are very similar. In addition, travellers intensively depart during [7:20, 8:00], regardless of which traffic mode they chose, to maintain the opportunity to obtain free parking spaces and the flexibility of shifting to MRT or P+R.

The benefit of providing information about real-time parking lot occupancies is less significant than the authors expected, but it is reasonable and can be explained from two aspects. On one hand, if travellers fail to obtain free parking spaces today, the travellers will increase their predicted travel costs for DV on the following day due to the learning behaviour and then reduce their travel costs by adjusting their traffic mode choices. On the other hand, travellers will adjust their departure time choices to reduce travel costs when possible. The process of convergence after the oscillation of total travel costs, which are shown in Figure $3 a$, also supports 
Liang J, Zhang X, Yan H. Evaluating the Impacts of Parking App Services on Travellers' Choice Behaviour and Traffic Dynamics

Table 2 - Experimental results of five scenarios on the last day when $|D|$ is equal to 120

\begin{tabular}{|c|c|c|c|c|c|c|c|}
\hline Scenario & OD pair & $\overline{T C}^{w}$ & $\bar{n}_{M R T}$ & $\bar{n}_{D V}$ & $\bar{n}_{P+R}$ & Parking revenue & Average end time \\
\hline \multirow{4}{*}{ A } & $1 \rightarrow \mathrm{CBD}$ & $60,315.70$ & $1,103.19$ & 575.79 & 808.02 & \multirow{4}{*}{$18,814.08$} & \multirow{4}{*}{$9: 31$} \\
\hline & $2 \rightarrow \mathrm{CBD}$ & $70,601.10$ & $1,924.64$ & 442.91 & 804.45 & & \\
\hline & $3 \rightarrow \mathrm{CBD}$ & $86,323.50$ & $1,927.19$ & 716.48 & $1,008.34$ & & \\
\hline & Total & $217,240.30$ & $4,955.02$ & $1,735.18$ & $2,620.82$ & & \\
\hline \multirow{4}{*}{ B } & $1 \rightarrow \mathrm{CBD}$ & $60,324.50$ & $1,093.06$ & 572.35 & 821.59 & \multirow{4}{*}{$17,593.92$} & \multirow{4}{*}{$9: 28$} \\
\hline & $2 \rightarrow \mathrm{CBD}$ & $69,982.80$ & $1,930.22$ & 428.15 & 813.63 & & \\
\hline & $3 \rightarrow \mathrm{CBD}$ & $86,154.00$ & $1,914.42$ & 719.43 & $1,018.15$ & & \\
\hline & Total & $216,461.30$ & $4,937.70$ & $1,719.92$ & $2,653.37$ & & \\
\hline \multirow{4}{*}{$\mathrm{C}$} & $1 \rightarrow \mathrm{CBD}$ & $55,811.20$ & $1,069.48$ & 401.23 & $1,016.29$ & \multirow{4}{*}{0.00} & \multirow{4}{*}{$9: 55$} \\
\hline & $2 \rightarrow \mathrm{CBD}$ & $65,910.10$ & $1,611.90$ & 512.28 & $1,047.82$ & & \\
\hline & $3 \rightarrow \mathrm{CBD}$ & $83,893.30$ & $1,786.62$ & 586.49 & $1,278.89$ & & \\
\hline & Total & $205,614.60$ & $4,468.00$ & $1,500.00$ & $3,343.00$ & & \\
\hline \multirow{4}{*}{$\mathrm{D}$} & $1 \rightarrow \mathrm{CBD}$ & $62,788.70$ & $1,059.42$ & 626.20 & 801.38 & \multirow{4}{*}{$30,070.88$} & \multirow{4}{*}{$9: 27$} \\
\hline & $2 \rightarrow \mathrm{CBD}$ & $69,310.70$ & $1,914.42$ & 459.61 & 797.96 & & \\
\hline & $3 \rightarrow \mathrm{CBD}$ & $89,684.80$ & $1,853.07$ & 790.08 & $1,008.86$ & & \\
\hline & Total & $221,784.20$ & $4,826.91$ & $1,875.89$ & $2,608.20$ & & \\
\hline \multirow{4}{*}{ E } & $1 \rightarrow \mathrm{CBD}$ & $60,581.20$ & $1,112.71$ & 580.31 & 793.98 & \multirow{4}{*}{$21,603.36$} & \multirow{4}{*}{$9: 26$} \\
\hline & $2 \rightarrow \mathrm{CBD}$ & $70,215.90$ & $1,921.26$ & 457.26 & 793.48 & & \\
\hline & $3 \rightarrow \mathrm{CBD}$ & $86,547.30$ & $1,930.53$ & 732.47 & 989.00 & & \\
\hline & Total & $217,344.40$ & $4,964.50$ & $1,770.04$ & $2,576.46$ & & \\
\hline
\end{tabular}

Note: The units of $\overline{T C}^{w}$ and parking revenues are yuan/day, and the units of $\bar{n}_{M R T} \bar{n}_{D V}$, and $\bar{n}_{P+R}$ are travellers/day.

these two explanations. Hence, a traveller's risk of parking competition can be significantly reduced by the adjustments of traffic mode choices and departure time choices during day-to-day evolution. A similar phenomenon has also been found by Liang and Zhang [7], but travellers' departure time choices were not formulated and discussed in their research.

\subsubsection{Parking reservation services}

As parking reservation services are provided in scenario $\mathrm{C}$, the information of real-time parking lot occupancies is no longer necessary, and the parking fee is $\phi_{1}(d)=80$ yuan (see Table 1 ); thus, travellers will not choose DV if they fail to reserve free parking spaces. The results of scenario $\mathrm{A}$ and scenario $\mathrm{C}$ are compared, as summarized in Table 2.

It can be found that the total travel cost of the whole network on the last day in scenario $\mathrm{C}$ is significantly less than that in scenario A, saving approximately 12,000 yuan in this experiment. The reason for this savings is that 487.02 travellers who chose MRT and 235.18 travellers who chose DV have shifted to $\mathrm{P}+\mathrm{R}$, as a parking reservation service is provided in scenario $\mathrm{C}$. Moreover, the distributions of departure rates and the average travel costs in scenario $\mathrm{C}$ are also obviously different from those in scenario A, as shown in Figure $5 b$. The travellers who have successfully reserved free parking spaces will depart in a dispersed manner and later than others to reduce their travel costs. In other words, a parking reservation service is an effective method to reduce travel costs and encourage travellers to choose $\mathrm{P}+\mathrm{R}$ during the day-to-day evolution of traffic dynamics. Because travellers who have successfully reserved the parking spaces can depart later in a dispersed manner to reduce travel costs; others can also choose a suitable traffic mode in advance.

\subsubsection{Dynamic parking fees}

Scenario D and scenario E are designed based on scenario B. The only difference among the three scenarios is the values of parking fee $\phi(d)$, which are reported in Table 1. It should be noted that $\phi_{2}(d)$ and $\phi_{3}(d)$ can be distinguished by their periods. The results of scenarios B, D and E presented in Table 2 and Figures $6 a-6 d$ show that the total travel costs in both scenarios $\mathrm{D}$ and $\mathrm{E}$ are greater than that in scenario $\mathrm{B}$ because travellers in scenario $\mathrm{D}$ and scenario $\mathrm{E}$ prefer to choose DV and depart intensively. Similar evidence is found when comparing the departure rates in other two OD pairs. This finding indicates that dynamic parking fees encourage more travellers to take risks to compete for free parking spaces during the evolution of traffic dynamics, and this competition will ultimately lead to the oscillation of travel costs. Moreover, the oscillation in scenario $\mathrm{E}$ is less than that in scenario $\mathrm{D}$ due to the longer period. Other dynamic parking fees $\phi(d)$ with 


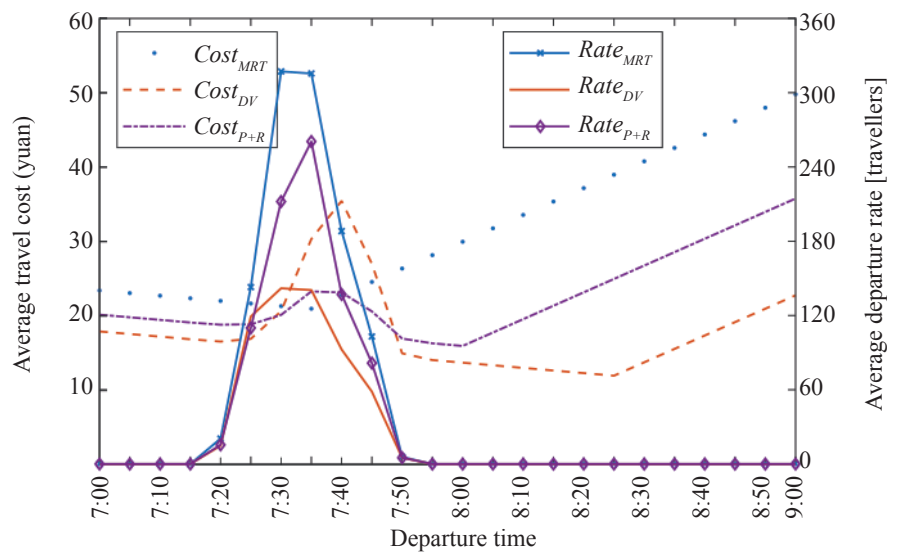

a) Scenario $B$

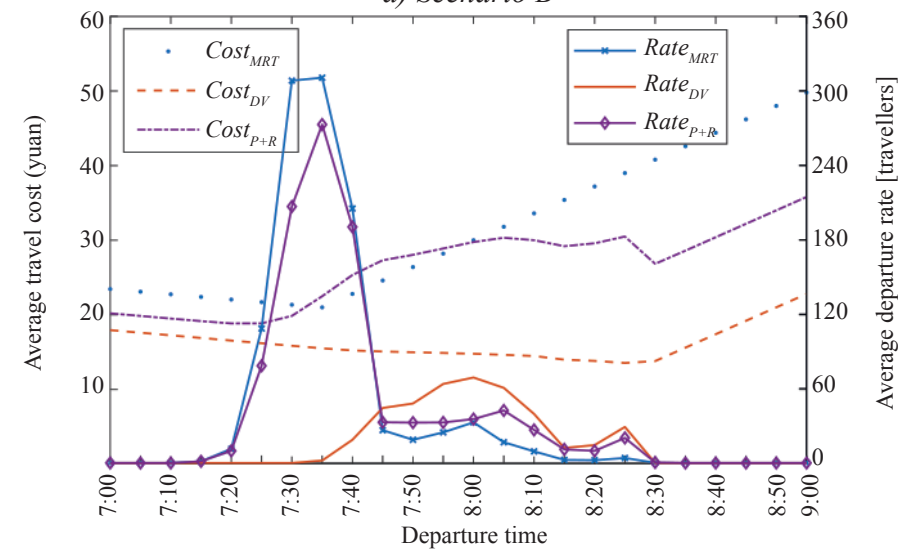

b) Scenario $C$

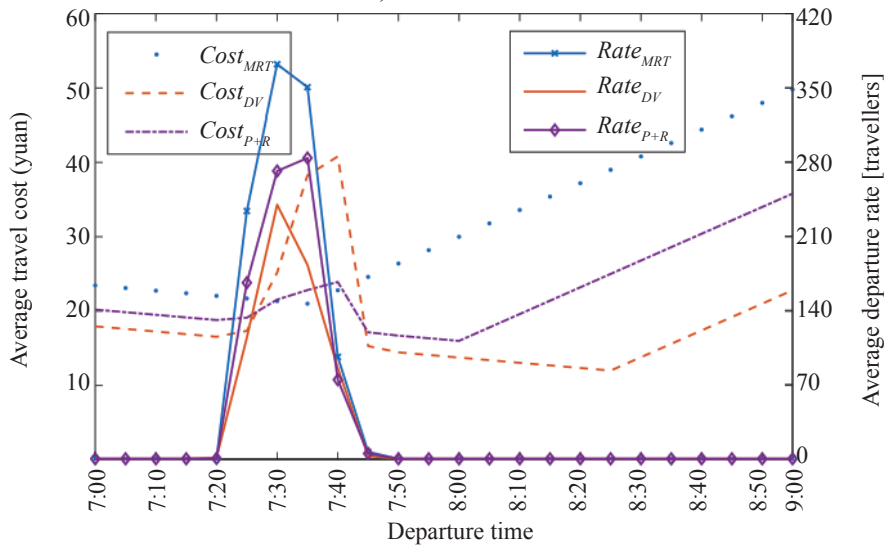

c) Scenario D

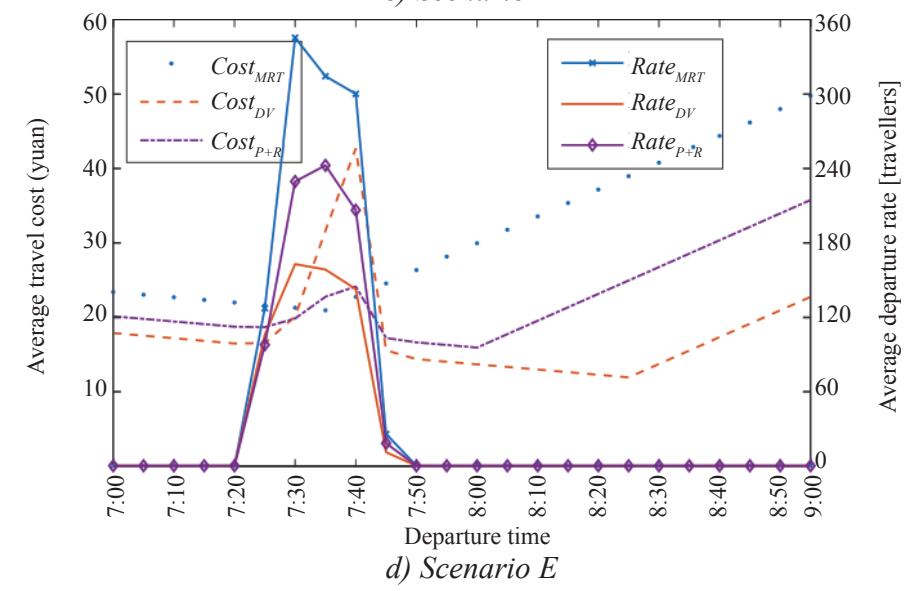

Figure 5 - Average travel costs and departure rates of travellers in scenarios $B, C, D$ and $E$ in $O D$ pair $1 \rightarrow C B D$ 
different periods have also been tested, and this phenomenon also exists in those cases. Based on the above observations, it can be observed that the period of dynamic parking fees is an important issue due to the impacts on traffic. Namely, the shorter the period, the larger the oscillation in travel costs. However, these impacts can be smoothed to some extent by the evolution of traffic dynamics.

\subsection{Impacts of parking app services on traffic dynamics}

In this paper, three types of parking app services have been investigated, namely the provision of information on real-time parking lot occupancies (scenario B), a parking reservation service (scenario C) and a dynamic parking fee displaying service (scenario D and scenario E). These services primarily affect travellers' traffic mode choices and departure time choices, which ultimately affect traffic dynamics. It was observed that the average end times and congestion levels were quite different among the five scenarios. The average end time in scenario $\mathrm{C}$ was obviously greater than that in the other scenarios (see Table 2) because travellers could reserve parking spaces in advance in the parking app such that they could depart and arrive at their destination later than other travellers. Moreover, the congestion level in scenario $\mathrm{C}$ was the lowest among the scenarios because the travellers' departure time period was expanded to $[7: 15,8: 30]$ in scenario C (see Figures $5 a-5 d$ ). Due to length limitations, the in-flows/ out-flows are not plotted and instead only some details in Table 2 and Figures $5 a-5 d$ are provided.

\section{CONCLUSION}

The popularity of parking apps not only provides travellers with various parking services but also brings new challenges to classic traffic models. In this paper, a novel traffic simulation model is developed for a many-to-one multimodal network provided with three types of parking services in a parking app. The three types of parking services are some well-known parking management policies, namely, the provision of information on real-time parking lot occupancies, parking reservation and the display of dynamic parking fees. After that, five scenarios are designed to describe the traffic dynamics when implementing parking app services. Finally, the impacts of the three parking services on travellers' choice behaviour and traffic dynamics are analysed based on the numerical results of the five scenarios.
The numerical results show that the proposed model can rationally simulate the travellers' behaviour and the traffic dynamics. Comparing the results of the five scenarios, the conclusions can be summarized as follows: (1) Travellers' risks of parking competition can be reduced by the provision of information on real-time parking lot occupancies, although the effectiveness is substantially smoothed during the evolution of traffic dynamics; (2) A parking reservation service is an effective method to reduce travel costs and encourage travellers to choose $\mathrm{P}+\mathrm{R}$ during the evolution of traffic dynamics. The reason lies in the travellers' behaviour, as the travellers who have successfully reserved a parking space prefer to depart later and in a dispersed manner to reduce travel costs, while others can also choose suitable traffic modes (except DV) in advance. (3) Dynamic parking fees lead to the oscillation of day-today traffic dynamics and an increase in travel costs. However, the period of dynamic parking fees is a key issue in the oscillation of travel costs. To some extent, the shorter the period, the higher the oscillation.

Potential applications of the proposed model may include the modelling and simulation of a traffic system provided with advanced parking app services, especially when the supply of parking resources is insufficient and the uncertainties caused by travellers' behaviour are substantial. Moreover, this model can be a useful tool for analysing the effectiveness of parking management strategies, such as allocating parking permits/coupons, travel limits on licence plates or vehicle types, and other customized services provided by parking apps.

\section{ACKNOWLEDGEMENTS}

The work described in this paper was jointly supported by the National Natural Science Foundation of China (No. 71531011, 71890970/71890973), a project sponsored by the program of Shanghai academic research leader, and the funding from the International Exchange Program for Graduate Students, Tongji University (No. 2018020031).

\section{梁晶晶, 张小宁, 间黄}

\section{停车 $\boldsymbol{A P P}$ 中的信息服务对出行者的选择行为和 交通动态的影响评估}

\section{摘要}

作为智能交通系统的辅助产品, 停车A $p p$ 已经成 为了交通管理者实施停车政策的便利平台。在本文 中, 我们提出了一个交通仿真模型, 用于评估停车 
$A p p$ 中信息服务的提供对出行者的选择行为和交通动 态的影响。该模型中考虑了如下三种停车服务: 实 时剩余停车位信息的提供, 停车位预订服务和动态 停车费的信息显示。此外, 该模型还考虑了多种出 行者行为, 例如: 出行方式选择、出发时刻选择和 出行者的学习行为。数值实验的结果表明: 实时剩 余停车位信息的提供在短期内有助于降低出行者使 用商业停车位的比例, 从而降低出行成本, 但经过 长期的交通动态演化之后, 此效果将不再显著; 停 车位预订服务可以有效地降低出行成本, 并且有助 于鼓励出行者进行 “停车换乘”; 动态停车收费通常 会导致出行成本的增加、增大交通动态的波动性, 并且使出行者的选择行为更加难以趋于稳定。本文 提出的仿真模型是一种分析停车 $A p p$ 中信息服务的有 效工具, 也为停车管理政策的评估提供了方法和借 鉴。

\section{关键词}

停车应用服务; 停车政策; 交通动态; 出行者的选择行为; 学习行为理论

\section{REFERENCES}

[1] Vickrey WS. Congestion Theory and Transport Investment. American Economic Review. 1969;59(2): 251-60. Available from: https://www.jstor.org/stable/1823678

[2] Ibeas A, Cordera R, Dell'Olio L, Moura JL. Modelling demand in restricted parking zones. Transportation Research Part A: Policy \& Practice. 2011;45(6): 485-98. Available from: doi:10.1016/j.tra.2011.03.004

[3] Sheffi Y. Urban Transportation Networks: Equilibrium Analysis with Mathematical Programming Methods. Prentice-Hall; 1984.

[4] Szeto WY, Wong SC. Dynamic traffic assignment: model classifications and recent advances in travel choice principles. Central European Journal of Engineering. 2012;2(1): 1-18. Available from: doi:10.2478/s13531011-0057-y

[5] Caicedo F. Real-time parking information management to reduce search time, vehicle displacement and emissions. Transportation Research Part D. 2010;15(4): 22834. Available from: doi:10.1016/j.trd.2010.02.008

[6] Yang J, Li X, Liu S. A Reservation Strategy Model of Finite Berth Based on Active Parking Guidance and Information System. Information Security and Assurance. 2009: 1-4. Available from: https://ieeexplore.ieee.org/ document $/ 5072670$

[7] Liang JJ, Zhang XN. A Simulation Model for Traffic Mode Choice under the Provision of Real-time Parking Lot's Information. Journal of Transportation Systems Engineering \& Information Technology. 2018;18(2): 529. Available from: http://www.tseit.org.cn/CN/Y2018/ V18/I2/52

[8] Kaspi M, Raviv T, Tzur M. Parking reservation policies in one-way vehicle sharing systems. Transportation Research Part B. 2014;62(2): 35-50. Available from: doi:10.1016/j.trb.2014.01.006

[9] Qian Z, Rajagopal R. Optimal dynamic pricing for morning commute parking. Transportmetrica. 2015;
11(4): 291-316. Available from: doi:10.1080/23249935. 2014.986671

[10] Chaniotakis E, Pel AJ. Drivers' parking location choice under uncertain parking availability and search times: A stated preference experiment. Transportation Research Part A. 2015;82: 228-39. Available from: doi:10.1016/ j.tra.2015.10.004

[11] Mahmassani HS, Liu YH. Dynamics of commuting decision behaviour under advanced traveller information systems. Transportation Research Part C: Emerging Technologies. 1999;7: 91-107. Available from: doi:10.1016/ S0968-090X(99)00014-5

[12] Liu Y. Comparative Study of the Effects od Auditory, Visual and Multimodality Displays on Drivers' performance in Advanced Traveller Information Systems. Ergonomics. 2001;44(4): 425-42. Available from: doi:10.1080/00140130010011369

[13] Dingus TA, Hulse MC, Mollenhauer MA, Fleischman RN, Mcgehee DV, Manakkal N. Effects of age, system experience, and navigation technique on driving with an advanced traveler information system. $H u$ man Factors. 1997;39(2): 177-99. Available from: doi: 10.1518/001872097778543804

[14] Nie X, Zhang HM. A Comparative Study of Some Macroscopic Link Models Used in Dynamic Traffic Assignment. Networks \& Spatial Economics. 2005;5(1): 89115. Available from: doi:10.1007/s11067-005-6663-6

[15] Liu W, Geroliminis N. Doubly dynamics for multi-modal networks with park-and-ride and adaptive pricing. Transportation Research Part B: Methodological. 2017;102: 162-79. Available from: doi:10.1016/j.trb.2017.05.010

[16] Shen W, Zhang HM. What Do Different Traffic Flow Models Mean for System-Optimal Dynamic Traffic Assignment in a Many-to-One Network? Transportation Research Record, Journal of the Transportation Research Board. 2008;2088(2088): 157-66. Available from: doi:10.3141/2088-17

[17] Zhang X, Yang H, Huang HJ. Improving travel efficiency by parking permits distribution and trading. Transportation Research Part B. 2011;45(7): 1018-34. Available from: doi:10.1016/j.trb.2011.05.003

[18] Wang J, Zhang X, Zhang HM. Parking permits management and optimal parking supply considering traffic emission cost. Transportation Research Part D. 2018. Available from: doi:10.1016/j.trd.2016.02.005

[19] Cantarella GE. Day-to-day dynamic models for Intelligent Transportation Systems design and appraisal. Transportation Research Part C: Emerging Technologies. 2013;29(1): 117-30. Available from: doi:10.1016/j. trc.2012.03.005

[20] Kroese DP, Brereton T, Taimre T, Botev ZI. Why the Monte Carlo method is so important today. Wiley Interdisciplinary Reviews Computational Statistics. 2014;6(6): 386-92. Available from: doi:10.1002/wics. 1314

[21] Liu W, Li X, Zhang F, Yang H. Interactive travel choices and traffic forecast in a doubly dynamical system with user inertia and information provision. Transportation Research Part C: Emerging Technologies. 2017;85: 71131. Available from: doi:10.1016/j.trc.2017.10.021 